\title{
La Poesía y el Espacio Interior: una aproximación a la lectura atenta desde la didáctica de la lengua inglesa y tres haikus de E. Pound
}

\author{
Francisco José Francisco Carrera *
}

\section{Resumen}

El presente trabajo se ocupa de cómo podemos desarrollar una lectura más atenta de textos poético-literarios en el marco del aprendizaje de un segundo idioma. Partiendo de la necesidad de desarrollar una mirada atenta para así poder entender mejor nuestro mundo interior, el mundo del otro y la interrelación entre ambos, proponemos el uso del haiku como poesía mínima y contenida para con ello potencial valores positivos de atención y cuidado hacia el otro y su entorno. Se explicita también el esbozo de un dispositivo didáctico en relación con cómo usar el haiku en la clase de inglés a partir de tres poemas del poeta estadounidense Ezra Pound. Se concluye enfatizando la importancia de la poesía como creadora de espacios de interiorización personal y procesos de lectura lenta y atenta que redundarán en una mejor comprensión de lo observado, algo esencial para cualquier profesional de la educación.

Palabras clave: $\quad$ Poesía - Haiku - Interiorización - Lengua inglesa - Lectura atenta 


\title{
Poetry and Inner Space: an approach to close reading from the teaching of the English language and three haikus by E. Pound
}

\author{
Francisco José Francisco Carrera *
}

\begin{abstract}
This paper is concerned with how we can develop a more attentive reading of poeticliterary texts in the context of learning a second language. Starting from the need to develop an attentive look in order to better understand our inner world, the world of the other and the interrelation between both, we propose the use of haiku as a minimal and contained poetry in order to potentialize positive values of attention and care towards the other and its environment. We also outline a didactic device in relation to how to use haiku in the English class based on three poems by the American poet Ezra Pound. It concludes by emphasizing the importance of poetry as a creator of spaces for personal internalization and processes of slow and attentive reading that will result in a better understanding of what is observed, something essential for any education professional.
\end{abstract}

Keywords: $\quad$ Poetry - Haiku - Internalization - English language - Close reading 


\section{Introducción}

Desde que la pandemia del Covid-19 estalló afectando a todas las sociedades planetarias, todos hemos tenido que replantearnos nuestras dinámicas personales $y$ sociales en un grado u otro. Sin duda, el efecto que la situación tuvo en nuestros sistemas educativos hizo que profesores de todo el mundo y desde todos los niveles nos pusiéramos manos a la obra para comprender e interpretar cómo podíamos adaptar nuestras labores docentes de la mejor manera posible al contexto crítico que se nos imponía. He aquí el germen del presente trabajo, pues nace de esa época convulsa que, en muchos sentidos, todavía está presente en nuestro día a día sin bien, afortunadamente, con diversos signos de mejora. Durante los meses del confinamiento estricto en España (desde el 13 de marzo al 20 de junio), como tantos otros docentes, tuvimos que adaptar nuestras labores educativas a un formato estrictamente on-line. De esta manera, decidimos trabajar con nuestros alumnos una serie de ideas y conceptos a través de materiales poéticos mínimos en lengua inglesa. Dichos alumnos cursaban el Grado de Educación Primaria para ser futuros maestros en dicho ciclo educativo. En las páginas que siguen, planteamos algunas de las reflexiones que nos llevaron a ello. A la vez se esboza la propuesta educativa que se realizó partiendo del haiku como género poético mínimo y contenido en general y sobre la poesía de Ezra Pound en particular.

Pues bien, partimos de la base de que en nuestros sistemas educativos $y$, por extensión, en nuestras sociedades cada vez cuesta más prestar una atención pura y constante a cualquier hecho. Esto también se muestra en los modos en que nos enfrentamos a los textos, especialmente a los textos escritos. Acaso porque estamos dejando una cultura basada en el texto escrito para ir hacia una nueva oralidad digital (Rodríguez, 2019), acaso porque el flujo constante de información por los medios digitales nos hace estar absolutamente fuera de nosotros mismos (Williams, 2021). La cuestión es que estamos perdiendo una capacidad que habíamos ido adquiriendo a lo largo de siglos de tradición lectora.

No estamos diciendo que haya que detener el progreso tecnológico por sus efectos perniciosos. Esto no es cierto y además no es posible. Simplemente consideramos que es importante reflexionar sobre lo que está pasando al respecto para ser muy conscientes de todas las aristas de cualquier fenómeno tecnológico que impacte en nuestros procesos de cognición. Al fin y al cabo, somos de la opinión de que todo progreso que se precie ha de ser retroprogreso (Pániker, 2016), como veremos con más detalle un poco más adelante.

Para empezar, consideramos que la problemática ha sido muy bien señalada por Maryanne Wolf (2009), quien ha recalcado que una lectura profunda (deep reading) se hace necesaria para poder acceder de manera adecuada a los textos pero que desgraciadamente este tipo de lectura pausada y atenta es cada vez menos frecuente por el esfuerzo y tiempo que implica su desarrollo. Así, hablando del lector distraído (distracted reader), Wolf enfatiza el hecho de que la lectura en internet, con toda la proliferación de hiper vínculos, hace que no podemos llegar a centrarnos en ningún 
aspecto por un tiempo prolongado. Wolf, en cualquier caso, es optimista al entender que evolucionaremos hacia algo que fusionará la atención de la lectura profunda y la rapidez de la adquisición de mucha cantidad de información de manera rápida. Lo cierto es que, aunque queremos compartir esta visión propuesta por Wolf, no podemos olvidar lo siguiente: "si la primera "brecha digital" marginó a quienes no tenían acceso a la información, la brecha actual marginará a quienes sean incapaces de prestar atención" (Williams, 2021, p.40). En otras palabras, puede que logremos aunar atención y rapidez, pero creemos que solo podremos hacerlo si trabajamos muy en serio en cómo enfocar y mantener esa atención.

En cuanto a las ventajas de una lectura atenta, vemos al menos tres. Un entrenamiento para mirar el mundo con atención, un aprendizaje de saberes para la vida y un desarrollo de la mirada interior, por así decirlo. En cuanto a la primera idea, cabe decir que el ser capaces de leer atentamente nos abre las puertas para usar esa misma atención al texto como mundo y esto implica que podremos ser mucho más cuidadoso en nuestras relaciones con nuestro entorno, entorno que además compartimos con el resto de los seres humanos y especies del planeta. Por lo que respecta a la segunda, creemos con Mèlich (2019) que los textos literarios nos ofrecen un buen número de aspectos que nos pueden llevar a leer mejor nuestras propias vidas; además, siendo como somos seres narrativos, el acceso a los géneros narrativos será lógico.

Por otra parte, afirma Han que esa narratividad ya no es posible porque "hoy vivimos en una época posnarrativa" (2021, p. 40), aunque esto no la convierte en lírica o dramática, quizás, diríamos, la literaturidad del mundo ya no es, o no es como la conocimos, metamorfoseó o está metamorfoseando en algo que todavía no podemos señalar con claridad, quizás por lo fluido de la época, trayendo a colación el concepto de "modernidad líquida" de Bauman (2012). Aquí, incidiremos en que somos seres narrativos, sí, pero también poéticos y por ello profundamente simbólicos y metafóricos. En cualquier caso, estas ideas nos llevan a la tercera ventaja que mencionábamos y es que el desarrollo de la mirada interior tiene que ver con una visión poética de nuestra vida, de profunda interiorización y recogimiento. Algo que radica en la esencia del poema. De la poesía y de su naturaleza pasaremos a hablar a continuación.

\section{Poesía y espacio interior}

Hablar del poema, de la naturaleza propia del poema, es algo siempre especialmente complicado. Ballart en El contorno del poema (2005) nos deja claro lo difícil que es delimitar lo que es propio y meramente propio del texto poemático. Uno roza el silencio aquí, quizás por la cercanía que guardan la mística y la poesía, pues ambas se embozan en el silencio para su enunciación (Beuchot, 2019).

Borges, por su parte, nos recordaba lo siguiente al hablar de esta cuestión: 
Esto significa que sabemos qué es la poesía. Lo sabemos tan bien que no podemos definirla con otras palabras, como somos incapaces de definir el sabor del café, el color rojo o amarillo o el significado de la ira, el amor, el odio, el amanecer, el atardecer o el amor por nuestro país. Estas cosas están tan arraigadas en nosotros que sólo pueden ser expresadas por esos símbolos comunes que compartirnos. ¿Y por qué habríamos de necesitar más palabras? (2001, p.34).

Apunta aquí Borges a una de las características básicas del poema, su naturaleza absoluta de objeto artístico por antonomasia. En este sentido no sería necesario definir el poema porque está por encima (en el sentido de estar más allá, de trascendencia) de esa verbalización. Sabemos de lo importante y no necesitamos mucha mediación al respecto para tenerlo claro, pero con todo, algo nos lleva a crear objetos bellos y a analizarlos, a glosarlos constantemente. Son rituales reconfortantes, meta-alegrías o meta-placeres en ese sentido. El arte verbal que nos ofrece el poema es un ejemplo claro, la poesía se esfuerza por darle ropaje lingüístico a lo inefable que es a la vez lo más mínimo, humilde y cotidiano. Esa sombra furtiva reflejada en un muro al atardecer, ese olor que captamos al pasar por un jardín en medio de una gran ciudad de cemento y metal, esas ensoñaciones que nos vienen lentas al tomar un café con un amigo, deteniendo el tiempo hiperacelerado en el que vivimos. Pero, en cualquier caso, a lo inefable, a lo que está más allá solo podemos ir desde lo que está más acá y es nombrable, de ahí el juego metalingüísticos del poema y de la literatura. La realidad y la percepción humana de la misma es la que es y eso mediatiza el acceso a ciertas profundidades que presentimos ineludiblemente. El poeta Vicente Gallego nos recuerda lo siguiente:

La verdad no tiene que ver con el consuelo ni con ninguna otra cosa, ni siquiera con la salvación, porque se lleva por delante al que pretendía ser salvado o consolado. No hay verdad que nos libre de los sabañones y los achaques, aunque sólo la verdad nos enseñe a celebrar la necesidad de nuestras dolencias y a reírnos del pijama de madera (2014, pp. 42 y 43)

Aquí sería conveniente por lo tanto traer a colación la visión Bonnefoy (2014) para quien la poesía es un acto de conocimiento que conforma un territorio interior dentro de cada uno. Aunque él se refiere más en concreto al acto de crear, nosotros consideramos que esas cualidades son extrapolables a la lectura de poesía.

Pero el poema también nos puede ayudar a volver a retomar el sentido positivo de la herida y del dolor como elemento catártico. Han (2021) insiste, muy acertadamente en nuestra opinión, en uno de sus últimos textos en que nuestras sociedades huyen constantemente del dolor y la negatividad. De este modo, por ejemplo, nos encontramos con que: 
La sociedad paliativa coincide con la sociedad del rendimiento. El dolor se interpreta como síntoma de debilidad. Es algo que hay que ocultar o eliminar optimizándolo. Es incompatible con el rendimiento. La pasividad del sufrimiento no tiene cabida en la sociedad activa dominada por las capacidades (Han, 2021, p. 14).

\section{El haiku en lengua inglesa y E. Pound}

El haiku es una modalidad poética de origen japonés que entronca con el Zen. Esto es así porque es un objeto de meditación que busca desvelar la verdad original y porque desarrolla cualidades relativas a la simplicidad, la naturalidad, la profundidad y la instantaneidad (Stryk e Ikemoto, 1981). Así, en el mundo literario de lengua inglesa, esta tipología poemática hace su aparición en el mundo de los "imagistas", en especial gracias a Ezra Pound pues será él quien ponga al haiku en un lugar de honor en las letras inglesas.

El haiku en inglés por antonomasia es el poema de Pound titulado "In a Station of the Metro", de 1916 y que reproducimos más abajo en el presente apartado. En cualquier caso, recordemos primeramente que los cinco idiomas principales en los que se ha adaptado el haiku son cinco: español, inglés, francés, portugués y alemán (Brower, 1992). Haciendo un poco de historia, conviene recordar que 1841 trajo un acercamiento del mundo oriental a Europa gracias a la famosa exposición sobre arte japonés que tuvo lugar en París; así, el interés por el país oriental pasó después a Inglaterra y gracias a los estudios de especialistas tales como W. G. Ashton o Basil Hall Chamberlain se le daría un importante impulso a la temática japonesa en el contexto de la lengua inglesa.

En cualquier caso, como decíamos, fue el poeta estadounidense Ezra Pound quien más hizo de manera concreta por la adopción del haiku en la lengua inglesa. Junto a él hubo otros autores importantes tales como A. Lowell o R. Aldington, pero siempre se reconoce esa labor pionera al autor nacido en el estado de Idaho. Desde entonces, el haiku ha estado más o menos presente en las literaturas en lengua inglesa. Un buen ejemplo de esto lo encontramos en el libro Haiku in English, publicado en 2013 y editado por Kacian, Rowland y Burns. En dicha obra encontramos una profusa selección de haikus que van desde el primero de Ezra Pound hasta obras de autores del siglo XXI. Dicho compendio viene asimismo con una introducción al respecto y un profundo estudio sobre el haiku en inglés por lo que remitimos al lector interesado a dicha obra en concreto.

Por lo que a nosotros respecta, queremos ahora indicar tres obras de Ezra Pound como materia prima para poder trabajar la lectura atenta. Para ello, nos hemos servido de la cuidada edición de sus poemas breves publicada en Hiperión en el año 2000 y que lleva por título Personae. Los Poemas breves. Dicha edición corrió a cargo de Lea Baechler y A. Walton Litz como revisores y fue traducida por Jesús Munárriz y Jenaro Talens. Los tres poemas elegidos son los siguientes: 


\section{IN A STATION OF THE METRO}

The apparittion of these faces in the crowd;

Petals on a wet, black bough.

\section{ALBA}

As cool as the pale wet leaves

of lily-of-the-valley

She lay beside me in the dawn.

\section{FAN-PIECE, FOR HER IMPERIAL LORD}

O Fan of White silk, clear as Frost on the Grass-blade, You also are laid aside.

Estos son los poemas que tendremos que tener en mente a la hora de presentar la propuesta didáctica que conforma la siguiente sección.

\section{Acerca de la lectura atenta: propuesta didáctica}

Ya decía Gadamer que "es cuestión de discernimiento (y no de enseñanza y aprendizaje) el reconocer la conveniencia de la aplicación de una regla general a una situación dada" (1996, p. 29); claro está que lo difícil aquí es saber cómo llegar a ese "discernimiento" del que habla el filósofo alemán. Por ello, como decíamos al principio del presente trabajo, el confinamiento debido a la emergencia sanitaria del Covid-19 nos pilló a todos envueltos en nuestros devenires más mundanos.

En nuestro caso, siendo nuestra actividad la docencia universitaria, entendimos que una buena manera de explorar la nueva situación era a través de un correlato objetivo a la manera eliotiana. Por ello elegimos los tres poemas antes mencionados (una zona pequeña, muy pero que muy mínima) como modo de exploración y material educativo. El grupo con el que trabajamos estaba en su último año de formación en la Facultad de Educación (grado de Educación Primaria) y el confinamiento les llegó cuando estaban realizando sus prácticas docentes en los colegios.

Como sus tutores, se espera de los docentes universitarios que vayan guiando a los futuros docentes en sus prácticas a través de seminarios. Consideramos interesante ofrecerles contenidos adicionales que puedan ayudarles a ver todo el proceso enseñanzaaprendizaje desde unas perspectivas más holísticas. Por ejemplo, puede ser útil trabajar materiales de índole literaria. Por ello la elección de los haikus antes mencionados. Los alumnos con los que trabajábamos eran especialistas en lengua inglesa (iban a ser docentes de ese idioma), por lo que presentar también un género perteneciente a otra cultura (la japonesa) ayudaba a presentar la necesidad de unas aulas abiertas y multiculturales. Al ser poemas mínimos, recordemos que el haiku es un breve poema que 
presenta una estructura silábica de 5-7-5 generalmente dispuestos en tres versos, el alumnado no tuvo problema en acercarse a dicha propuesta.

El haiku es un poema tan mínimo que es útil para trabajar diversos aspectos en la enseñanza de una segunda lengua (sobre todo el vocabulario) a la vez que se estimula la creatividad y se presenta una tercera cultura involucrada en el proceso (obviamente, siempre y cuando no sea nuestra meta enseñar japonés como segunda lengua). Es un texto poético tradicional que tiene aspectos de contenido y estructura muy marcados, lo que hacen que el alumno tenga que adaptarse a un contexto dado, reforzando el entendimiento del género (en la lectura) y el impulso creativo (en su creación). Nos referimos aquí a la necesidad de que en un haiku aparezcan, por ejemplo, la palabra estacional (kigo) o la pausa reveladora (kireji).

En cuanto a las bases epistemológicas para nuestra propuesta partían de los siguientes autores e ideas esenciales que ahora explicitamos. Por un lado, la necesidad de que el lector desarrolle una mirada atenta (Esquirol, 2006) desde el silencio (d'Ors, 2015). Con ello, lo que pretendemos es que el lector desarrolle el hábito de enfrentarse a un haiku con calma y una mente sosegada, hay que prestar mucha atención a cada detalle y hay que hacerlo desde la serenidad que proporciona el silencio. Además, es importante desarrollar una lectura analógica que evite de univocismos y equivocismos, que sea prudente y respetuosa, para ello partimos de Beuchot (2009) y su hermenéutica analógica.

De este modo, es bueno recordar al lector que su mundo, el mundo del autor y el mismo mundo del texto han de entrar en un diálogo, repetimos, prudente y respetuoso. No nos cabe duda de que unos hábitos de percepción asentados en la mirada atenta y el silencio son sin duda muy importantes. Por último, se promueve en este sentido una lectura retroprogresiva del texto, siendo el haiku un modelo absolutamente tradicional, aunque percibido por una mentalidad moderna, la de los lectores de nuestro tiempo. Aquí funciona también un sentido dialógico del proceso emprendido, esto es así porque, como nos recuerda Pániker (2016), todo progreso real es retroprogreso y es conveniente no perder de vista el origen al ir avanzando.

Pasamos a exponer brevemente algunas de las características más interesantes que presenta el uso del haiku en el proceso de adaptación de materiales didácticoeducativos. Para empezar, el haiku nos lleva ante un caso extremo de brevedad textual, bien es cierto que esto es así para toda la poesía lírica en general, pero en el caso que nos ocupa esto es una máxima compositiva, en tres versos y 17 sílabas se ha de expresar todo lo que se quiera expresar y esto expone al lector ante una situación de profunda concentración de significado; esto es así porque estamos ante un caso arquetípico de intensidad lírica, como decimos, aquí no hay espacio para muchos juegos retóricos, se ha de destilar el contenido en una forma hiper-breve lo que lo hace idóneo para diversas secuencias didácticas que quieran trabajarse con cierta agilidad. Al fin y al cabo, el haiku 
se basa en una aparente simplicidad anclada en la cotidianeidad de sus contenidos, pues busca presentar el aquí y el ahora si mayor mediación o artificio. Ahora bien, decimos "aparente" porque como ha señalado Barthes (2014), el haiku no tiene nada de fácil y esa sensación de que cualquiera puede escribirlo sin esfuerzo es muy engañosa.

En las secuencias didácticas que busquen trabajar contenidos concretos, es importante observar que, al estar basado en el mundo natural, el haiku es idóneo para crear dispositivos didácticos de aprendizaje del vocabulario relativo a dicho campo semántico. El mundo concreto del haiku hace también que la enseñanza de los sustantivos se presente como una actividad fácil de explotar. Por último, cabe señalar el estímulo creativo que surge en la lectura del haiku, sobre todo cuando te lleva también a la creación de ese tipo de poesía.

Para concluir esta sección, proponemos de manera concreta dos tipos de actividades. Una basada en la lectura atenta y otra en la creación analógica y retroprogresiva de haikus. Con la intención de ofrecérselos a nuestros alumnos, recopilamos tres de los haikus más conocidos de Ezra Pound que, como dijimos anteriormente, es quien adaptó y adoptó el haiku en la literatura en lengua inglesa.

Teniendo en cuenta que el poema titulado "In a Station of the Metro" es considerado como el primer haiku en inglés, este poema tendrá que ser leído por todos los alumnos sin excepción. La idea es que de manera muy atenta todos ellos lean el poema y escriban un breve ensayo que cubra lo objetivo y lo subjetivo: básicamente han de decir qué dice el poema y cómo lo dice (lo objetivo) y qué les hace sentir (lo subjetivo). Al leerlo todos, todos tendrán algo que decir y al ponerlo en común se podrá crear un diálogo al respecto que redundará en una mejor comprensión del objeto estudiado.

Es importante recordar aquí que interesaría en este momento hablar un poco con los estudiantes sobre si alguien conocía este tipo de poemas, si los habían leído ya, incluso saber si alguien ha escrito ya algún haiku. Esto se desarrollaría en una primera sesión. Para concluir esta sesión se les pedirá que elijan uno de los otros dos poemas seleccionados para hacer de nuevo una lectura muy atenta a través de la cual tendrán que volver señalar aspectos objetivos y subjetivos, esto se realizará durante una segunda sesión. Se entronca por tanto con lo que hicimos durante la primera sesión. Una cosa que debemos recordar aquí es que en poesía toda palabra importa, importa y mucho, por eso al leer poesía en otro idioma uno ha de tener especial cuidado con los significados para tener claro qué no está queriendo decir el texto y el autor a través de este.

Por último, pasaríamos a la parte creativa del proceso y para ello tendríamos una tercera sesión que vendría a unir todas las anteriores en un momento final. Los alumnos tendrían que crear su propio haiku a partir de los conocimientos que han ido adquiriendo en las sesiones anteriores.

La idea es desarrollar estos contenidos y actividades de manera intensa en un corto espacio de tiempo. Como comentábamos, nosotros lo hicimos en un período de tres meses, de abril a junio de 2020, durante el confinamiento por la pandemia del Covid-19. 
Tres sesiones es una secuenciación adecuada y con un espacio de entre 1 y 3 semanas entre sesión y sesión para que los alumnos dispusieran de tiempo propio de trabajo para "macerar" todo, para "cocerlo a fuego lento", si se nos permiten los símiles culinarios al respecto.

En este proceso creativo se funde una atención lectora y una atención creadora en un terreno literario que sirve de preparación para las experiencias vitales que todos enfrenamos antes o después, pues es bueno que seamos unos lectores atentos y unos creadores cuidadosos para con el texto de la vida. Si además tenemos en cuenta que los lectores con los que trabajamos de manera concreta para los ejercicios que hemos propuesto van a ser educadores (maestros de primaria), esto se hace todavía más evidente pues toda clase es un texto de gran complejidad y los docentes son a su manera metahermeneutas que han de desentrañar una gran cantidad de significados en sus lecturas de todo lo que pasa en un aula (Francisco Carrera y García Sanz, 2018).

\section{Conclusiones}

Por fin, llegando a este espacio liminar y conclusivo, nos queda recopilar una serie de ideas. Para empezar, Luri (2018) se refiere a un círculo virtuoso de la lectura que hace que cuanto más hayamos leído, mejor leamos los nuevos textos a los que nos enfrentemos, es por lo tanto una acumulación de capas o estratos culturales, algo que también tendría sentido al hablar de la atención.

Si estamos acostumbrados a leer con atención en todo momento, esto será sin duda más fácil de conseguir. Por su parte, Patino (2019) incide en que la atención del ser humano está siendo desplazada por pequeños impactos que hacen de ella un foco cambiante sin rumbo fijo, por así decirlo. Es como si no se pudiera mantener, como si hubiésemos perdido el control sobre ella, lo que nos lleva a pensar que quizás nunca tuvimos su control y que por eso mantener la atención es un arte muy pero que muy sutil.

Cuando todos demandan nuestra atención, en el fondo nuestra atención se pierde y no es de nadie, pero sobre todo deja de ser "nuestra". Por ello, como dice Williams (2021) es un momento esencial para aprender a gestionar la atención, para así no perderla o dejarla en manos de otros, llegando por lo tanto a un sentido de autorregulación de esta.

La búsqueda de un terreno híbrido y fluido en la transmisión didáctica nos lleva constantemente hacia otros límites, un poco en el sentido de la didáctica transmoderna de la que habla Jasso Ayala (2016); también es lo que se pretende con las propuestas educativas de Gómez Redondo (2021) quien enfatiza la importancia de la atención al contexto cambiante de nuestro mundo y cómo la pedagogía puede ir iluminando veredas al respecto.

Por fin, y para concluir, creemos que Williams (2021) ha señalado un aspecto esencial en todo lo que hemos venido tratando de recoger aquí. Para el autor, sólo 
seremos capaces de hacer algo de valor si antes nos vemos capaces de poder centrar nuestra atención en aquello que realmente es digno de ella y del esfuerzo que implica tal proceso. Esta idea es esencial y con ella cerramos el presente trabajo, es nuestra obligación como educadores el identificar aquellos aspectos valiosos para nuestros educandos como seres sociales y como individuos en desarrollo. De esta manera conformaremos nuestras actuaciones didácticas y los dispositivos creados para sus transmisiones de la mejor manera posible.

Ahora más que nunca esto es una necesidad y ha de hacerse con mucha prudencia y cautela pues estamos en un momento en el que la velocidad con la que se transmite la información va en aumento con cada avance tecnológico, teniendo en cuenta además que, si esta velocidad se torna excesiva, dicha información no será procesada de una manera coherente por todo aquel expuesto a ella (Williams, 2021). Confiemos, por lo tanto, en que podamos encontrar el tiempo y la forma para poder transmitir una visión profundamente humana, cuidadosa, atenta al otro y al mundo, siempre sin olvidarnos de mantener un profundo deseo porque nuestra propia llama individual no deje de iluminar y calentar el camino que hemos de recorrer, solitarios y acompañados a la vez, pues tal es la experiencia del viaje a través de las vidas humanas desde el nacimiento hasta la frontera final de la muerte.

\section{Referencias bibliográficas}

AYALA, J. (2016). "El fundamento "trans" para la didáctica transmoderna" en CAUCE. Revista internacional de Filología, Comunicación y sus Didácticas, № 39.

BALLART, P. (2005). El contorno del poema. Barcelona: Acantilado.

BARTHES, R. (2014). El imperio de los signos. Barcelona: Seix Barral.

BAUMAN, Z. (2012). Vida líquida. Barcelona: Planeta.

BEUCHOT, M. (2009). Tratado de hermenéutica analógica. Hacia un nuevo modelo de interpretación. México, D.F.: Ítaca.

BEUCHOT, M. (2019). "Hermenéutica analógica del silencio" en Francisco Carrera, F. J. (Ed.) Palabras de nunca y de nada. Herramientas didácticas y filosóficas para la aplicación del silencio en la sociedad y la educación. Soria: Ceasga.

BONNEFOY, Y. (2014). El territorio interior. Madrid: Sexto piso.

BORGES, J. L. (2001). Arte poética. Seis conferencias. Barcelona: Crítica.

BROWER, G. L. (1992). Haiku in Western Languages. Londres: The Scarecrow Press.

D'ORS, P. (2015). Biografía del silencio. Madrid: Siruela.

ESQUIROL, J. M. (2006). El respeto o la mirada atenta. Barcelona: Gedisa. 
FRANCISCO CARRERA, F. J. y GARCÍA SANZ, R. (2018). “El docente como metahermeneuta: hacia una phrónesis didáctico-interpretativa en la profesión educativa" en FRANCISCO CARRERA, F. J. Y BUENO RUIZ, I. (Eds.) An Approach to Society and Education from Hermeneutics. Soria: Ceasga.

GADAMER, H. G. (1996). El estado oculto de la salud. Barcelona: Gedisa.

GALLEGO, V. (2014). Vivir el cuerpo de la realidad. Barcelona: Kairós.

GÓMEZ REDONDO, S. (2021). "La educación bajo la lente viral: entre la hipertrofia, la desigualdad y la incertidumbre" en COCA, J. R. y GARCÍA GÓMEZ, BL. (Coords.) Entre los límites del SARS-CoV-2. Sociedad, comportamiento y retos futuros. España: Ediciones del Serbal.

HAN, B. C. (2021). La sociedad paliativa. Barcelona: Herder.

KACIAN, J., ROWLAND, P. Y BURNS, A. (2013). Haiku in English. The First Hundred Years. Nueva York: Norton.

LURI, G. (2018). El deber moral de ser inteligente. Conferencias y artículos sobre la educación y la vida. Barcelona: Plataforma Editorial.

MÈLICH, J. C. (2019). La sabiduría de lo incierto. Lectura y condición humana. Barcelona: Tusquets.

PÁNIKER, S. (2016). Asimetrías. Hibridismo y retroprogresión. Barcelona: Kairós.

PATINO, B. (2019). La civilización de la memoria de pez. Pequeño tratado de la atención. Madrid: Alianza.

RODRÍGUEZ, J. (2019). Primitivos de una nueva era. Cómo nos hemos convertido en Homo digitalis. Barcelona: Tusquets.

STRYK, F y IKEMOTO, T. (Eds.) (1981). The Penguin Book of Zen Poetry. Londres: Penguin.

WILLIAMS, J. (2021). Clics contra la humanidad. Libertad y resistencia en la era de la distracción tecnológica. Barcelona: Gatopardo.

* Francisco José Francisco Carrera: Doctor en Ciencias de la Educación por la Universidad de Salamanca y Licenciado en Filología Inglesa por la Universidad de Valladolid. Es profesor de la Facultad de Educación de Soria y profesor-tutor en el Centro Asociado de la Uned en la misma ciudad para el Grado de Estudios Ingleses. Ha coordinado los volúmenes colectivos Hermenéutica, Educación y Sociedad (2017), An Approach to Society and Education from Hermeneutics (2018) y Palabras de nunca y de nada. Herramientas didácticas Filosóficas para la aplicación del silencio en la sociedad y la educación (2019). Asimismo, es autor de numerosos trabajos dentro de los campos disciplinares de la didáctica de las lenguas, la filología y la crítica literaria. Ha propuesto en varios de sus trabajos académicos publicados en revistas científicas que el docente sea considerado como un metahermeneuta y un sanador socio-educativo. [E-mail: franciscojose.francisco@uva.es] 